\title{
Study on Heat Exchange of convection heating surface of a Pressurized
}

\section{Oxygen Enriched Coal-fired Boiler}

\section{LIBAO YIN ${ }^{1} \&$ HANG ZHAO ${ }^{2}$ \& ZHENGYANG GAO ${ }^{2}$ \& XINXIN MENG ${ }^{2}$ \&}

\author{
SHUO $\mathrm{JI}^{2}$ \\ ${ }^{1}$ Guangdong Power Grid co., LTD Electric Power Research Institute, guangzhou, China \\ ${ }^{2}$ North China Electric Power University, Baoding, China
}

KEYWORD: pressurized oxy-fuel boiler; numerical simulation; heat exchanger; velocity of the flue gas

ABSTRACT: The technology of the oxygen enriched combustion is a very promising new power generation technology for cleaning coal. This paper takes a $300 \mathrm{MW}$ coal-fired boiler for study, calculates the properties of flue gas of the pulverized coal combustion under the air and oxygen and pressurized oxygen enriched $(\mathrm{CO} 2 / \mathrm{O} 2=70: 30,0.1 \mathrm{MPa} / 1 \mathrm{MPa})$ conditions by using ASPEN PLUS software, and then uses FLUENT software platform to simulate high temperature re-heater and Super-heater in three different conditions. At last,the high temperature re-heater and Super-heater are reformed to achieve the same effect of heat transfer in the air atmosphere by changing the flow rate of flue gas. The results show that when the combustion atmosphere varies from air to oxygen enriched air to pressurized oxygen enriched,the coefficient of heat transfer of high temperature re-heater and super-heater are increased, the radiation heat transfer coefficient are increased greatly, but the convective heat transfer coefficient are increased to a lesser extent.With the increase of gas flow rate, the reduction ratio of heat transfer area begins to increase slowly, then increases rapidly, and increases slowly after reaching $7 \mathrm{~m} / \mathrm{s}$.

\section{Introduction}

With the impact of global warming, CCS has become one of the hot topic in the research of $\mathrm{CO}_{2}$ currently ${ }^{[1-3]}, \mathrm{CO}_{2}$ concentration in conventional boiler is produced about $14 \%$, due to the low concentration, the recovery cost is very high; Adopting the oxygen enriched combustion technology, because of flue gas re-circulation, $\mathrm{CO}_{2}$ concentration in flue gas can reach more than $90 \%$, the flue gas discharged is cooled and compressed to liquid $\mathrm{CO}_{2}$, so it has become one of the effective methods for $\mathrm{CO}_{2}$ capture;Adopting the pressurized oxygen enriched combustion technology, from the air separation into the combustion of the furnace, and then to the gas compression and $\mathrm{CO}_{2}$ capture, the whole process is carried out under high pressure, thus avoiding two compression process about oxygen buck and boost smoke under high pressure, $\mathrm{CO}_{2}$ and $\mathrm{SO}_{2}$ in flue gas can be liquefied at room temperature,so the energy consumption is needed for the recovery of $\mathrm{CO}_{2}$ is greatly reduced. Due to the flue gas re-circulation, the NOx emission is reduced. The oxygen enriched combustion technology has developed into a very promising new power generation technology for cleaning coal ${ }^{[4-5]}$.

This paper takes a 300MW coal-fired boiler for study, according to the characteristics of the boiler convection heating surface flow and heat transfer, establishes the 3D geometric model of the power plant boiler convection heating surface, and then uses FLUENT software platform to calculate heat transfer of the flue gas and metal tube wall and steam, gets the variation of flue gas flow rate and the logarithmic mean temperature difference and heat transfer coefficient about high temperature re-heater and super-heater under the air and oxygen and pressurized oxygen enriched 
$\left(\mathrm{CO}_{2} / \mathrm{O}_{2}=70: 30\right)$ conditions, and then reform the high temperature re-heater and Super-heater by changing the flow rate of flue gas.

\section{Object of study}

In this paper, the object of study is a $300 \mathrm{MW}$ subcritical pressure natural circulation drum boiler.Because the basic structure of the boiler flue convection heating surface and the heat transfer process is similar, therefore, this paper simulated the high temperature re-heater and super-heater. The simulation takes a tube screen of the high temperature re-heater composed of 7 side by side pipe and has a total of 14 root canal along the direction of gas flow; a tube screen of the high temperature super-heater is composed of 4 side by side pipe and has a total of 16 root canal along the direction of gas flow; the structure size of high temperature re-heater and Super-heater is shown in table 1 .

Tab.1 The structure size of the heat exchanger

\begin{tabular}{|l|c|c|}
\hline Heating surface & $\begin{array}{l}\text { High temperature } \\
\text { re-heater }\end{array}$ & $\begin{array}{l}\text { High temperature } \\
\text { super-heater }\end{array}$ \\
\hline $\begin{array}{l}\text { The inner diameter } \\
\text { of the pipe } / \mathrm{mm}\end{array}$ & 55 & 43 \\
\hline $\begin{array}{l}\text { The pipe outer } \\
\text { diameter } / \mathrm{mm}\end{array}$ & 63 & 51 \\
\hline $\begin{array}{l}\text { Transverse pitch } \\
\mathrm{S}_{1} / \mathrm{mm}\end{array}$ & 228.6 & 152.4 \\
\hline $\begin{array}{l}\text { Longitudinal pitch } \\
\mathrm{S}_{2} / \mathrm{mm}\end{array}$ & 114 & 102 \\
\hline
\end{tabular}

\section{Simulation model}

According to the structure characteristics of high temperature re-heater and super-heater of the power plant boiler,three-dimensional geometric model of convective heating surface is established, figure 1 is the physical model.
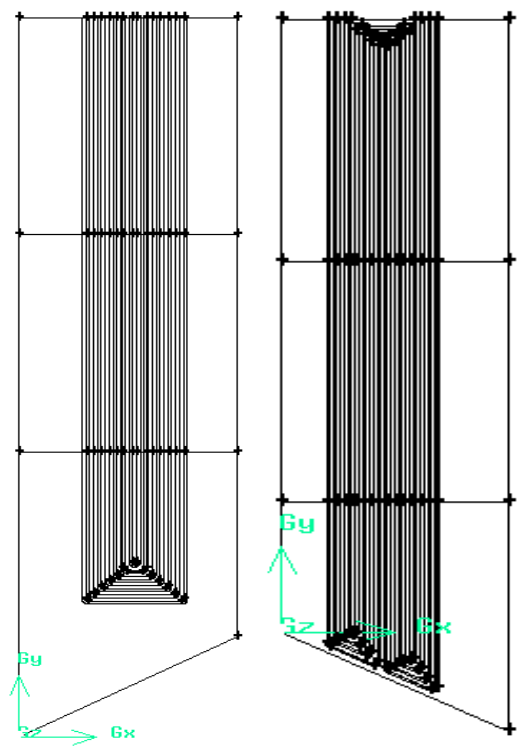

Fig.1 physical model

In the simulation of convection heating surface, the flue gas properties of the 
conventional air combustion is calculated by conventional method, the flue gas properties is calculated by using the ASPEN PLUS software under oxygen rich atmosphere ${ }^{[6]}$, the flue gas properties include density, specific heat capacity at constant pressure, viscosity, thermal conductivity coefficient and Prandtl number, calculated by using the thermodynamic method PR-BM.

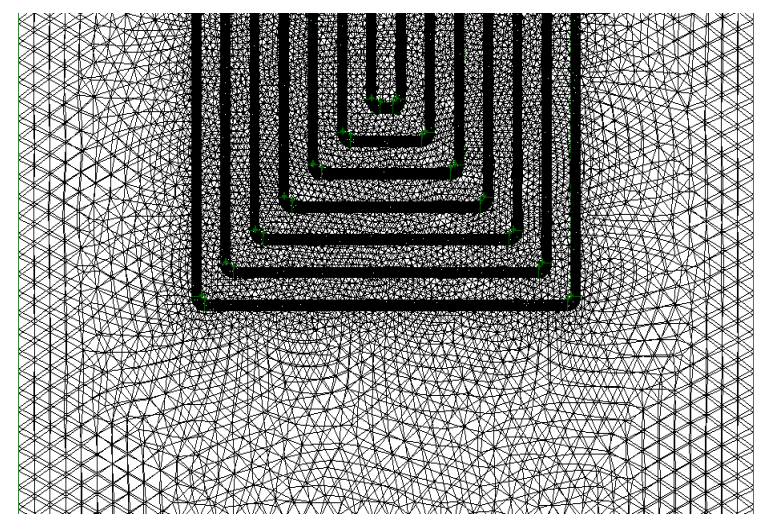

Fig.2 the partial view of the meshing

Steam flow zone is meshed by using a mixture of mainly tetrahedral mesh, flue gas flow area is meshed by using mesh size function method. The mode is divided into different numbers of grid simulation with different parameters. The simulation results are compared to validate the correctness of the grid. The partial view of the meshing is shown in Figure 2.

The simulation process by using the steady state solution of the function, the steam entrance is set as the boundary of the steam quality flow entrance, the mass flow of single root canal for high temperature re-heater and super-heater are $0.5617 \mathrm{~kg} / \mathrm{s}$ and $0.4519 \mathrm{~kg} / \mathrm{s}$, respectively pressure are $3.905 \mathrm{MPa}$ and $17.886 \mathrm{MPa}$, the fuel gas entrance is set as the boundary of the entrance velocity, velocity of flue gas are $9.6 \mathrm{~m} / \mathrm{s}$ and $10.6 \mathrm{~m} / \mathrm{s}$ respectively,entrance temperature are $1151 \mathrm{~K}$ and $1061 \mathrm{~K}$, the outlet of steam and flue gas are set as the boundary of pressure outlet, outlet steam pressure are respectively $3.725 \mathrm{MPa}$ and $17.5 \mathrm{MPa}$, the flue gas outlet pressure are slightly negative pressure. Pipe wall surface heats by using the coupled mode, screen walls are set for the symmetric boundary, the other wall is set at room temperature.

\section{THE results and analysis OF The calculation}

Figure 3 shows the changes of velocity of flue gas under different combustion atmosphere, when the structure of the heat exchanger is constant. Under the air and oxygen and pressurized oxygen enriched $\left(\mathrm{CO}_{2} / \mathrm{O}_{2}=70: 30\right)$ conditions, the velocity of flue gas for the re-heater are respectively $9.6 \mathrm{~m} / \mathrm{s}, 7.0321 \mathrm{~m} / \mathrm{s}, 0.7091 \mathrm{~m} / \mathrm{s}$, the velocity of flue gas for super-heater are $10.6 \mathrm{~m} / \mathrm{s}, 7.783 \mathrm{~m} / \mathrm{s}, 0.7816 \mathrm{~m} / \mathrm{s}$.Compared with air, flue gas velocity are reduced at about $26.75 \%$ and $92.62 \%$ under the oxygen and pressurized oxygen enriched $\left(\mathrm{CO}_{2} / \mathrm{O}_{2}=70: 30\right)$ conditions. It is because 


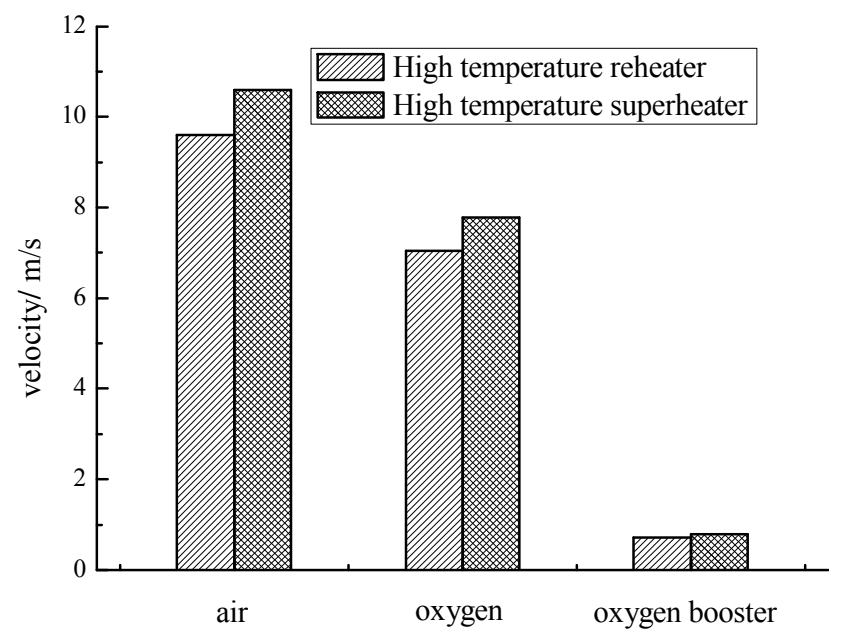

Fig. 3 the variation of the flue gas flow rate

that the gas of the combustion varies from the air into the mixing of $\mathrm{CO}_{2}$ and $\mathrm{O}_{2}$ under the condition of oxygen enrichment combustion, resulting in flue gas quantity generated less, flue gas velocity decreases. with pressure increasing, flue gas density changes, volume flow becomes smaller,flue gas flow rate decreased significantly ${ }^{[7]}$. This will inevitably lead to dramatic changes in the coefficient of heat transfer.

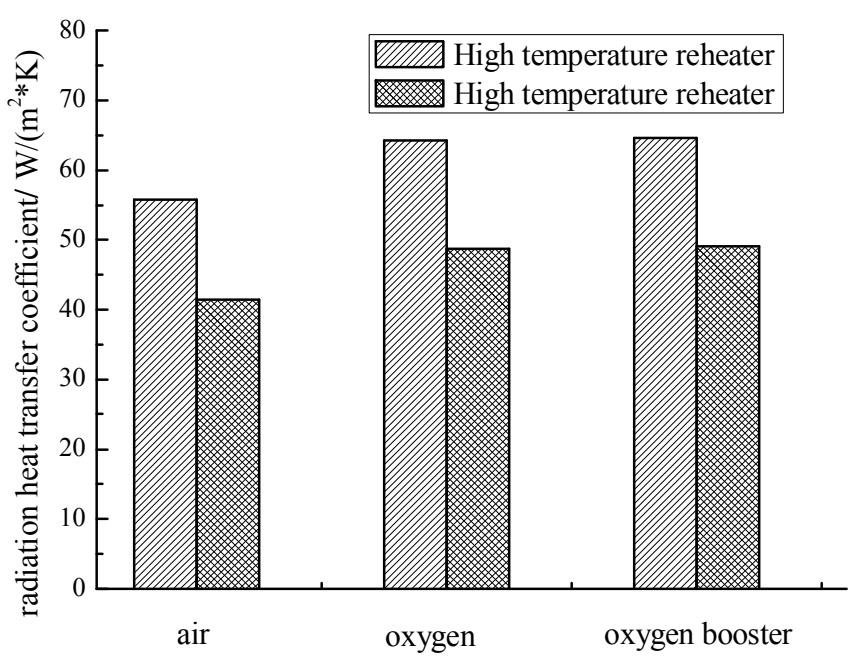

Fig.4 the variation of radiation heat transfer coefficient 


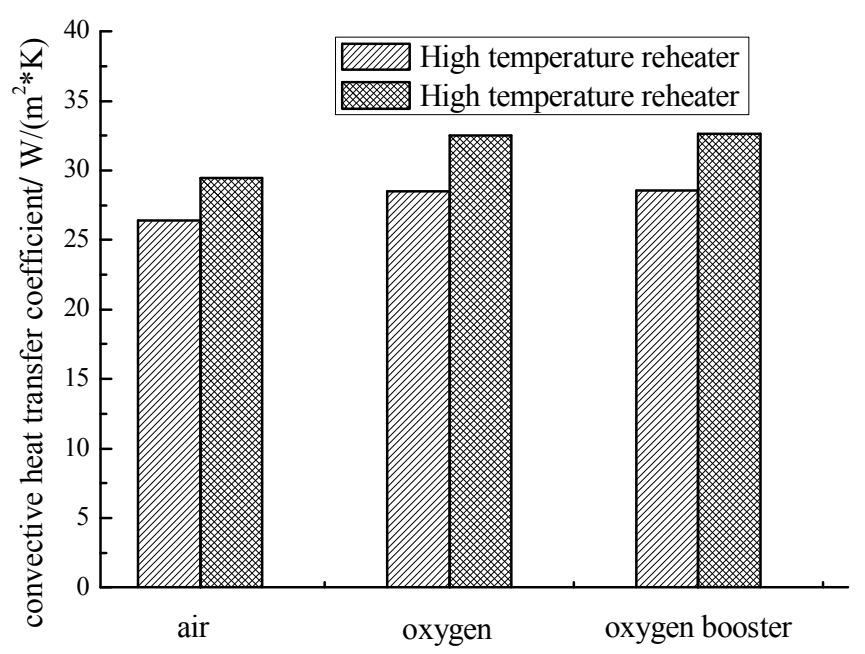

Fig. 5 the variation of convective heat transfer coefficient

Figure 4-5 shows the variation of radiation heat transfer coefficient and convective heat transfer coefficient in different combustion atmosphere, when the structure of the heat exchanger is constant. when the combustion atmosphere varies from air to oxygen enriched air to pressurized oxygen enriched,the coefficient of heat transfer of high temperature re-heater and super-heater are increased, the radiation heat coefficient are increased greatly, but the convective heat transfer coefficient are increased to a lesser extent. Compared with air atmosphere, the radiation heat transfer coefficient and the convective heat transfer coefficient are increased significantly greater. This is because the main component of flue gas generated in air is $\mathrm{N}_{2}, \mathrm{~N}_{2}$ has no radiation and absorption, but the main component of flue gas generated in oxygen rich condition is $\mathrm{CO}_{2}, \mathrm{CO}_{2}$ is three atomic gas with strong radiation and absorption capacity, so the heat transfer capability enhances under aerobic conditions than that under the air conditions. With the increase of the pressure, the gas density increases, velocity decreases, resulting in the Reynolds numbers of the flue gas remain unchanged, but the gas thermal conductivity increases with the increase of pressure, the convection heat transfer of the fuel gas enhances.

Compared with the high temperature re-heater, radiant heat transfer coefficient of the high temperature super-heater is less,but convective heat transfer coefficient is larger. This is because super-heater locates after high temperature re-heater, the temperature of flue gas is relatively low, the velocity of flue gas is relatively high, but the overall heat transfer coefficient of high temperature re-heater and super-heater have little difference.

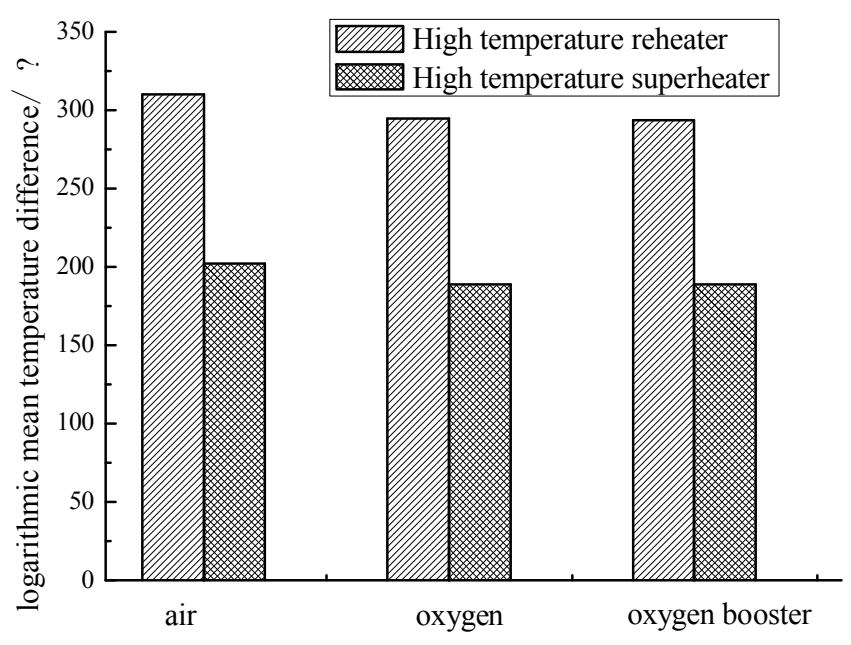

Fig.6 variation of the logarithmic mean temperature difference 
The effect of heat exchanger is not only affected by the convection and radiation of flue gas, but also related with the logarithmic mean temperature difference of heat exchanger. To achieve the same effect of heat transfer in the air atmosphere, logarithmic mean temperature difference must be considered. Figure 6 shows the variation of the logarithmic mean temperature difference in different combustion atmosphere, it can be seen from the figure, logarithmic mean temperature difference of the same heat exchanger in different combustion atmosphere changes little, but Logarithmic mean temperature difference at high temperature re-heater is higher than that at high temperature super-heater.

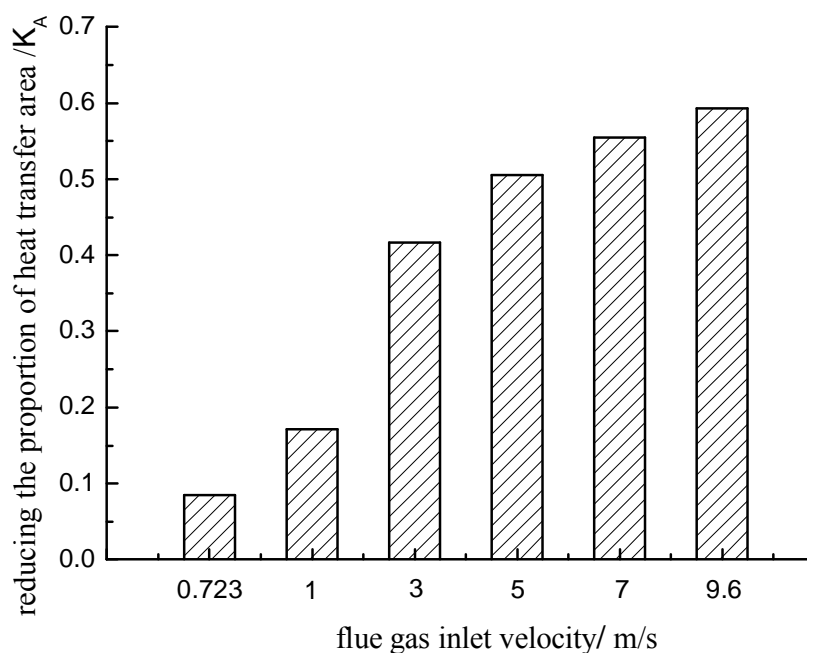

Fig. 7 the reduction ratio of high temperature re-heater area

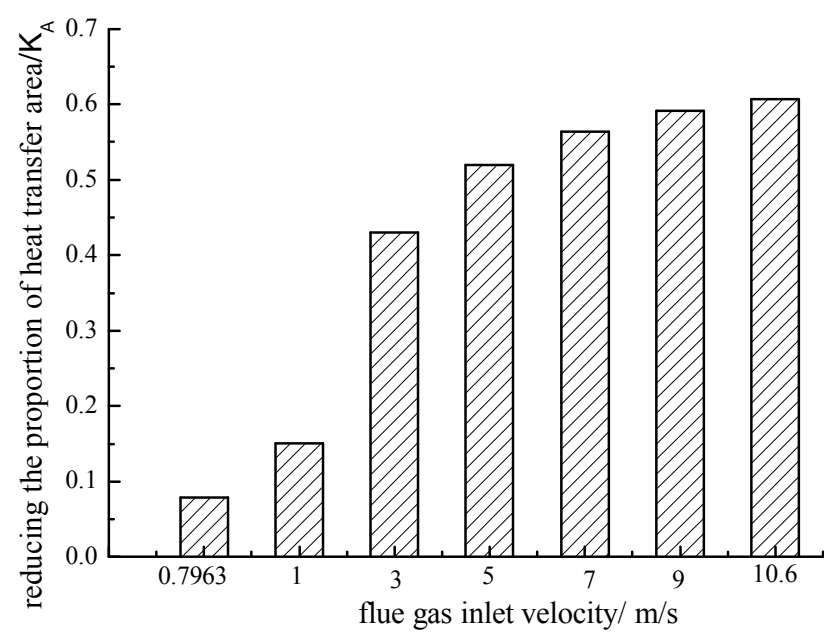

Fig. 8 the reduction ratio of high temperature super-heater area

Figure 7-8 show the change of the heat exchange area of high temperature re-heater and Super-heater required,respectively for the pressurized oxygen enriched combustion atmosphere, achieving the same effect of heat transfer ${ }^{[8]}$. It can be seen from the graph, the

heat transfer area of the heat exchanger under pressurized oxygen enriched combustion is less than the area under conventional air combustion, and the reduction ratio of heat exchange area of the high temperature re-heater and Super-heater is basically the same, with the increase of gas flow rate, the reduction ratio begins to increase slowly, then increases rapidly, increases slowly after reaching $7 \mathrm{~m} / \mathrm{s}$. In the whole process, the process is the fastest from the $1 \mathrm{~m} / \mathrm{s}$ to $3 \mathrm{~m} / \mathrm{s}$, reducing the area of about $20 \%$. 


\section{Conclusion}

With increasing pressure, flue gas density changes,volume flow becomes smaller, flue gas flow rate decreased significantly. This will inevitably lead to dramatic changes in the coefficient of heat transfer.

when the combustion atmosphere varies from air to oxygen enriched air to pressurized oxygen enriched,the coefficient of heat transfer of high temperature re-heater and super-heater are increased, the radiation heat transfer coefficient are increased greatly, but the convective heat transfer coefficient are increased to a lesser extent.

Logarithmic mean temperature difference of the same heat exchanger in different combustion atmosphere changes little, but Logarithmic mean temperature difference at high temperature re-heater is higher than that at high temperature super-heater.

With the increase of gas flow rate, the reduction ratio of heat transfer area begins to increase slowly, then increases rapidly, and varies slowly after reaching $7 \mathrm{~m} / \mathrm{s}$.

\section{Acknowledgements} $-0130)$.

The paper is supported by South Network Technology Project K-GD2014-178 (GD2014-2

\section{References}

[1] Hong J,Chaudhry G,Brisson JG,et al. Analysis of oxy-fuel combustion power cycle utilizing a pressurized coal combustor [J].Energy,2009,34(9):1332-1340.

[2] Hong J,Field R,Gazzino M,et al.Operating pressure dependence of the pressurized oxy-fuel combustion power cycle[J].Energy,2010,35(12):5391-5399.

[3] Xiong Jie,Zhao Haibo,Zheng Chuguan,eta1.An economic feasibility study of $\mathrm{O}_{2} / \mathrm{CO}_{2}$ recycle combustion technology based on existing coal-fired power plants in China [J].Fuel,2009,88(6):1135- 1142.

[4] YAN Weiping.Reviews on prospects of clean coal power generation technology[J].Journal of North China Electric Power University,2008,35 (6):67-71.

[5] YAN Weiping,MA Kai, GAO Zheng yang, DONG Jinglan. Erosion of economizer tube bundles in pressurized oxy-fuel coal-fired boiler [J]. Journal of Xi'an Jiao Tong University, 2013, 47 (3): 53-59.

[6] MA Kai,YAN Weiping,GAO Zheng yang.Physical properties and convective heat-transfer coefficients of flue gas from pressurized oxy-fuel combustion [J].Journal of Power Engineering,2011,31(11): 861-868.

[7] GAO Zhengyang, XIA Ruiqing, YAN Weiping, MA Kai, FENG Wenhui, ZHANG Bowen. Heat Transfer Characteristics of Boiler Convective Heating Surface Under Pressurized Oxygen-fuel Combustion Conditions[J].Proceedings of the CSEE,2012,32(23):1-8

[8] MA Kai,YAN Wei-ping,GAO Zheng-yang,XU Jia-qing. Design and Optimization for Economizer of Pressurized Oxy-fuel Coal-fired Boilers[J].Journal of Power Engineering,2013,33(3):165-177 